\title{
Views of Teachers and Hostel Matrons on the Landscape of Substance Abuse Amongst the Youth in the Northern Region of Namibia
}

\author{
Janetta Agnes Ananias ${ }^{1}$, Jabulani Calvin Makhubele ${ }^{2}$, Miriam Winnie Hasheela ${ }^{1}$, Ndanyakuwa Ilonga Hamuse \\ Tiberia $^{1}$, Rachel Johanna Freeman ${ }^{1}$, Prudence Mafa $^{2}$, Frans Koketso Matlakala ${ }^{2}$, Beatrice Namoonga Chilwalo ${ }^{1}$, \\ Selelo Frank Rapholo ${ }^{2} \&$ Anesu Svinurai ${ }^{2}$ \\ ${ }^{1}$ University of Namibia, Private Bag 13301, Windhoek, Namibia \\ ${ }^{2}$ University of Limpopo, Private Bag X1108, Sovenga 0727, South Africa \\ Correspondence: Prof. J.C. Makhubele, University of Limpopo, Private Bag X1108, Sovenga 0727, South Africa.
}

Received: January 31, 2019 Accepted: April 8, 2019 Online Published: April 15, 2019

doi:10.5539/gjhs.v11n5p133 URL: https://doi.org/10.5539/gjhs.v11n5p133

\begin{abstract}
Aim: This research project aimed at exploring the views of secondary school teachers and hostel matrons on the landscape of substance abuse amongst the youth at a border town situated in the northern region of Namibia.

Method: In this qualitative study, in-depth interviews were conducted with secondary school teachers and hostel matrons, selected by means of a purposive sampling method from five schools representing state schools and private schools. Ethical approval was obtained from the University of Namibia's ethical approval committee, whilst permission to conduct the study was obtained from the Ministry of Education, Arts and Culture, Namibia. Participation was voluntary and based on informed consent.

Findings: The themes identified in the study were amongst others; the types of substances used by the youth, the use of substances on school premises and easy access/availability of substances.

Conclusion: The study concluded that substance abuse seems to be normalised in the community because of the excessive availability of alcohol in the community. The need for law enforcement and law reform as well as prevention programmes at all levels of society is highlighted.
\end{abstract}

Keywords: substance abuse, youth, secondary school teacher, learner, hostel matron

\section{Introduction}

Substance abuse is a growing global concern, causing $12 \%$ of deaths worldwide (Nowak, Papiermik, Mikulska, \& Czarkowska-Paczek, 2018). The use of substances amongst the youth is of particular concern in Namibia as it relates to many social problems such as crime and violence in society, affecting the academic performance of learners, involvement in motor vehicle accidents and leads to school dropout (Kauaria, Kaundjua \& Mufune, 2015; Chibaya, 2016). The most commonly used substances worldwide, are according to UNESCO/UNODC/WHO (2017) and Moss, Chen and Yi (2014) are alcohol, tobacco and cannabis.

The World Health Organization (WHO) estimates that there are about 2 billion people worldwide who consume alcoholic beverages, of whom 76.3 million are affected by alcohol-related disorders (WHO, 2018). The European School Survey on Alcohol and Drugs (ESPAD, 2015) revealed that nearly half of the students (47\%) reported alcohol use at the age of 13 or younger, while a total of $13 \%$ of the students reported having been intoxicated during the previous 30 days. In terms of alcohol abuse by young people, the WHO (2018) adds that more than a quarter of all 15 to 19 year olds worldwide are current drinkers and this amounts to 155 million adolescents (WHO, 2018). Lightfoot, Maree and Ananias (2009) argue that alcohol abuse in Namibian communities is also extremely high. A nationwide survey conducted by SIAPAC (2002), found that $55 \%$ of Namibian adults consumed more than 10 litres of alcohol per week. The Namibia Demographic and Health Survey carried out some years later in 2013 showed that Namibians continue to drink excessively, as the survey indicated that half of the women and $57 \%$ of men have drunk alcohol at some point in their lives (Ministry of Health and Social Services /Namibia Statistics Agency, 2014).

According to the Namibia Human Development report, the level of alcohol abuse amongst the young people in Namibia is quite high, with half of the 13 to 16 year old Namibians experimenting with alcohol (United Nations 
Development Programme [UNDP], 1999). The same pattern of excessive alcohol consumption also appears amongst the Namibian school children and youth, with a school based global survey data from UNESCO UNODC/WHO (2017) showing that one in four children between the ages of 13 and 15 years having used alcohol during the previous month. The types of alcohol consumed by Namibians include both bottled alcohol, such as wine, beer, vodka as well as traditional home brewed drinks such as tombo, ombike and omalovu (Lightfoot, Maree \& Ananias, 2009). Moreover, the global status report on alcohol and health in Namibia found that the preferred types of alcoholic beverages for Namibians are store-purchased beer (15\%), store-purchased liquor $(6 \%)$, and wine (2\%) (WHO, 2018). In addition, homemade brew seems to be the most significant type of alcoholic beverage in Namibia, which accounts for $67 \%$ of the total consumption (WHO, 2004). In line with more than one hundred countries worldwide that are have banned the purchase of alcohol by children (Morleo, Cook, Elliott, \& Phillips-Howard, 2013), the Namibian Liquor Act No 6 of 1998 also prohibits the selling of liquor to children younger than 18 years. A critical analysis of the Namibian Liquor Act by Barth and Hubbard (2009), implies that 18 -year olds may be present at a licenced establishment, and they may drink or possess alcohol, except that the act of purchasing alcohol by children younger than 18 years would be an illegal act. This therefore, is a grey area in the Namibian legislation that needs to be relooked at.

The European School Survey on Alcohol and Drugs (ESPAD, 2015) pointed out that smoking cigarettes is common amongst students, as more than one in five students smoked cigarettes at the age of 13 or younger. The ESPAD (2015) survey further highlighted the addictive nature of cigarettes and found that an average of $4 \%$ of students began to smoke cigarettes on a daily basis at the age of 13 or younger.

The use of tobacco is controlled by the Tobacco Control Act (Act No. 1 of 2010) of Namibia. The Namibian population shows some patterns where more men smoke cigarettes than women, as according to the Namibia Demographic and Health Survey (2013) it was found that $4 \%$ of women and $19 \%$ of men between the ages of 15 and 49 in Namibia smoke cigarettes. A UNESCO/ UNODC/WHO (2017) survey further revealed that tobacco is one of the first substances used by children and young people.

The most prevalent illicit drug used in most of the countries is cannabis (ESPAD, 2015; UNESCO/ UNODC/WHO, 2017). The European School Survey on Alcohol and Drugs (ESPAD, 2015) has found that on average $16 \%$ of the students had used cannabis at least once in their lifetime. The same survey found that about three in ten students (30\%) rated cannabis to be easily available. On average, $3 \%$ of the students reported that they had first used cannabis at the age of 13 or younger. In addition to cannabis, other illicit drugs used by students in the ESPAD survey (2015) are ecstasy, amphetamine, cocaine and LSD or other hallucinogens. Namibia is not a significant producer of cannabis, or of other illegal drugs, yet illegal drugs find their way into the country (Kazembe \& Neema, 2015). However, the use of cannabis amongst the Namibian school going children was rated as low (UNESCO /UNODC/WHO, 2017).

A legitimate concern around the use of substances amongst the youth is the age of initiation. School going learners seem to start using substances at a very tender age. In Zimbabwe, the mean age of alcohol initiation has been recorded as 12.86 years, while the average age for first tobacco use was 13.13 years, and that for cannabis stood at 14.6 years (Mudhovozi, Maunganidze, Maseko, Ngwenya, \& Netshikweta, 2014). Similar findings were found in the Namibian context in a UNICEF (2006) study, where a focus group of 10 to 14 year olds revealed that one in ten children had already used alcohol. According to UNICEF (2006), ten years is the average age that children start experimenting with alcohol in Namibia. Alcohol consumption seems to be on the increase amongst the Namibian school children. In 1992, only $19.8 \%$ of 13 to 16 year olds had experimented with alcohol. Six years later, in 1998, that number had risen to $50 \%$ (Strijdom \& Angell, 1998). The real threat about substance abuse amongst the youth is the gateway hypothesis, which according to Moss, Chen, and Yi (2014) and Nowak, Papiernik, Mikulska and Czarkowska-Paczek (2018), refers to the tendency amongst adolescents to start using legal substances such as alcohol and cigarettes, but to eventually cross over and progress to the use of illegal drugs such as cannabis.

This point of view is supported by a survey done in Poland by Nowak et al. (2018), and another study done in the Sub Saharan African region by Olawole-Isaac, Ogundipe, Amoo, Adeloye (2018), which found that alcohol use and cigarette smoking are more prevalent amongst adolescents, while the use of illegal substances are rather low. Although evidence exists that substance abuse amongst school going youth is on the increase, little research has been done on substance abuse amongst the youth in rural communities in general and border towns in particular. Prevention programmes and interventions may exist in urban areas whilst the same are non-existent in rural border town communities. Therefore, this paper aimed at exploring the views of secondary school teachers and hostel matrons on the landscape of substance abuse amongst the school going youth. 


\section{Methodology}

This qualitative study aimed at exploring the perceptions of secondary school teachers and hostel matrons on the landscape of substance abuse amongst secondary school learners from a rural community at a border town in northern Namibia. This paper was part of a bigger mixed method study that examined risk and prevalence factors of substance abuse amongst the youth in this particular border town. The study population consisted of secondary school teachers and hostel matrons from secondary schools in the border town. The researchers collected data through in-depth interviews with seven secondary school teachers and hostel matrons from five different schools. The teachers and matrons were purposefully selected based on their likelihood to have contact with a bigger learner population from their school.

The schools selected in this study were representative of both state schools and private schools. Ethical approval for this study was obtained from the ethical review committee of the University of Namibia. Furthermore, permission to conduct the study was obtained from the Ministry of Education, Arts and Culture. All the participants voluntarily consented to the interview by means of signing an informed consent form. To ensure confidentiality, the names and identity of the participants are not stated in this paper. A semi-structured interview schedule was used for the interviews, and the interviews were conducted at a convenient time during class free period from 3 to 7 September 2018. At least two to three members of the research team were present at all the interviews. Interviews were conducted in English, but participants were free to express themselves in Oshiwambo, a local language predominantly spoken in the area the research was undertaken. At least one member of the research team could speak the local language and translated back to English. Open-ended questions in the interview focussed on participants' understanding of the extent of substance abuse amongst the youth. All interviews were digitally recorded and transcribed verbatim. Participants' biographies varied in terms of management position held at the school and gender as well since three of the participants were male and four were female. The thematic analysis approach was used to analyse the data. Transcriptions were read in a line by line and word by word manner, to identify the preliminary themes and subthemes.

\section{Findings}

Data analysis identified three main themes, namely; types of substances used by the youth; use of substances on school premises, and excessive presence of liquor outlets.

\subsection{Types of Substances Used by Youth}

A major theme identified in this study described the various types of substances most likely used by the youth. Participants were asked about their knowledge on the various substances used by young people and they indicated that there are a variety of locally produced and imported types of beer, and a wide variety of wine, whiskey and brandy that the young people are using. One participant listed the types of alcohol used by the youth as follows:

"Beer is the first one, and then they also drink, Castle Lager,... wine,...iya, the one in the green bottle and Capenheimer. Those are some... even the bottles we found on the school premises. Sometimes we can pick them up." (sic)

Another participant added:

"on the types of alcoholic beverages that are consumed by the youth, you know most of them they like beers, for the South African beer, there is Carling Black Label and Tafel Lager and ee... and Navaras. Navaras is a castle wine, it is sort of sparkling wine iya, and Tassenberg, this is a red dry wine. Those are the most, most aaa.." (sic)

The alcoholic beverages indicated by the two participants can be bottled, but some participants mentioned that some alcoholic beverages that are packaged in small plastic sachets and sold at a cheaper price are also available in the community. One participant brought along to the interview setting some empty plastic sachets to demonstrate that the alcoholic liquor in the plastic sachets can be of different kinds of brandy, whiskey and wine. The participants further indicated that school children are also exposed to a traditional brew called tombo and that some of the learners even brought tombo to school. The Liquor Act No 6 of 1998 of Namibia defines tombo as "the traditional or home-brewed alcoholic drink, also known as sorghum beer, made from a fermentation of mahango, sorghum or other cereal or vegetable matter, with or without additives". One participant explained:

"we have this traditional drink, this homebrew like omahoongo (amarula homebrewed) you know ee. When omahongo is prepared the first part of it apparently is not sooo... alcoholic kind of, like even the parents themselves they are the one who offer this omahoongo to.. to learners and to them maybe it is seen as a not a problem, but as for me alcohol is just alcohol, even if maybe is a little concentrated or too much concentrated." (sic) 
According to Shikoyeni (2017), the production of home-brewed beverages is closely connected to food production in urban and rural areas in Namibia. This can be ascribed to the difficulty for some people in the community to make a distinction as to the stage the homebrew is no longer a nutritional drink but an alcoholic beverage. Different from the alcoholic beverages that school going youth are exposed to, children as young as those at the toddler phase, may have been fed tombo by a mother or other caregiver. One participant stated:

"Teen mothers give their small children tombo."

Most of the participants were of the view that traditional brews are not the preferred alcoholic drink for school going children but these are rather taken by out of school youth and school dropouts. One participant said:

"It is normally consumed by the dropout youth. You won't find easily a school going child drinking tombo. At school this moment in fulltime? No no. you won't find them drinking tombo easily like that. But those who will find on those bars are those have left school." (sic)

Another participant corroborated this by stating:

"Tombo is consumed by school dropouts."

The findings align with the results of Maree et al. (2008) who found that younger people will prefer to take alcoholic drinks in bottled format, while traditional brews are mostly taken by older people instead of the young people. The Namibia Human Development report also found that traditional brews are not the preferred choice of drink for children between the ages of 13 to 16 years, while men between 25 and 30 years have shown a steady increase in showing interests to drink traditional brews (UNDP, 1999). The use of tobacco was not a very prominent issue raised in the study but smoking of cigarettes by young people was mentioned by a few participants. A specific tobacco product named Yes is a very cheap cigarette which is most likely sneaked in from across the borders and its distribution is thus not controlled by the Namibian legislation. One participant stated:

"kids are smoking ehhhh... these cigarettes called "YES" when you go to other countries or any other town."

Another participant added:

"Like, a Yes cigarette only cost 1 NAM dollar.

A UNESCO/ UNODC/WHO (2017) survey revealed that tobacco is one of the first substances used by children and young people. The use of illegal drugs amongst the youth has also been stated as a matter of concern. Some description was provided about the illegal drugs that were found in the possession of learners. One participant said:

"it is like a powder or dry leaves, iya, those ones they will put in a plastic and then they will share with others..... Yes, sometime they are the ones who bring these to school.

Cannabis, also called as dagga, was found to be the most common illegal substance used in Namibia (Maree et al., 2008; Chibaya, 2016). Kazembe and Neema (2015), claim that Namibia is a drug transit haven for drugs that are destined for other lucrative markets particularly in the SADC region and in Africa in general. Thus, cheap alcohol in plastic sachets, cheap cigarettes that are imported illegally and illegal drugs have found their way into the Namibian territory and they are being used by the youth. Being found in possession of illegal drugs is a criminal offence which can lead to prosecution in Namibia. Incidences of learners smoking cannabis at school were reported by one secondary school teacher, who said the following:

"They (learners) smoke cannabis in the toilets. We caught them (learners), we took the stuff (drugs)

Another participant stated:

"we are currently having two learners who are in prison. They are using marijuana,"

According to Chibaya (2016), a direct consequence of using illegal substances such as cannabis is getting into conflict with the law, which was indeed confirmed in the present study. Except for cannabis, other types of drugs were not mentioned in this study. Perhaps this is because of the rural community where the study was conducted, and that perceptions of adults and not the children themselves were taken.

\subsection{Use of Substances on School Premises}

The school management has to ensure that school learners are protected from substance abuse by creating a conducive educational environment that is free from tobacco, alcohol and other drugs (UNESCO/UNODC/WHO, 2017). However, participants reported with dismay that some learners are taking substances to school and that they are also using substances at specific locations at school. Participants mentioned in particular that learners bring traditional brews to school which they drink during break time at school. Poverty, lack of food at home and also ignorance on the actual alcohol content of traditional brews seem to be the reasons why parents may send their 
children to school with traditional brews with potential alcohol content. One participant stated:

I identified containers having tombo for example, you do not get to get the reasons why the person comes with tombo, maybe there is no food at home, maybe it is just a drink like any other drink, one may not really tell like in case of home aa.. brew drinks."

Participants reported that children are introduced to alcohol when adults who are consuming alcohol send their children to buy alcoholic drinks at drinking outlets. These grownups may then also reward the children with alcoholic drinks.

This is supported by one participant that stated:

"... and our elders they are the ones that are consuming tombo. Sometime they are too weak to move to a cuca shop and they send children to go and pick for them. Once they put in a container and the container is full then...the... the...the...the cup is left halfway then the remaining will be given to the child who came to pick."

Participants explained that tombo is not sold in a sealed container but it is served in an open jug. Some children who are sent to buy tombo may taste it while carrying it after they have been sent to buy the tombo by grownups. One participant averred:

"parents should not send children to go collect tombo for them. Because in the process some children will be tempted too...to test and once you test that one, you are gone into the ditch for the rest of their life."

In the absence of any mechanisms to control traditional homemade brews (WHO, 2018); offering traditional brews for children's consumption could pose a threat to the health and wellbeing of children. According to the nationwide HIV and AIDS study on the knowledge, attitudes and practices (KAP study 2002), $57 \%$ of the respondents believed that it was easy for the youth to get access to home brewed alcohol in their community, while $49 \%$ of the respondents agreed that very young children were given home brewed alcohol to ease their hunger or to stop them from crying (SIAPAC, 2002). Participants reported that some learners may be using substances during school hours. The study revealed that learners may request to be excused from a class or from school to use substances at locations out of sight of the public, such as toilets. One of the participants echoed:

"You will believe that if the school gate is not locked you will see them giving excuses no...no...I am sick. Grannies said I must go back. But if you research very well they don't, they are not sick they go and get alcohol"

In the event that school management may suspect that learners are bringing substances to school, the school bags of learners may be inspected for any substances or other restricted objects. The school management has to be cautious whenever they inspect the school bags of learners. The findings revealed that school going youth carry substances in their school bags to school. This was stated by one participant:

"At my school we do an uninformed search, but every time you do this uninformed search like you search all the bags you know try to see all things which are not good there in the bags, and we always get alcohol there iya...especially those in small sachets, always. So, one may say no...it is not...not common but why do we always get alcohol when we search the bags.

These findings are corroborated by Ndondo (2016), who reported that learners in South African schools are offered, sold and given illegal drugs which are used on school premises or before learners attend school. Findings in a Namibian study done by Chibaya (2016), also confirm that secondary school learners are taking illegal drugs on school premises during break times. Findings by Alhyas et al. (2015) in a study on the perceptions of adolescents on substance abuse in Dubai confirmed that learners hide cigarettes and other drugs in their school bags, and Alhyas et al. (2015) thus suggested that regular inspections of school bags should be carried out. In a comparative analysis between South Africa and the United States of America by Joubert, Sughrue and Alexander (2013) on the search and seizure of drugs, it was found that secondary school learners' teachers and principals have frequently found it necessary to search learners and to remove from their possession items which might be harmful to them or other learners. Participants reported that some learners may have abused substances to such an extent that they have reached the level of addiction where they have reached the level where they cannot live without alcohol or drugs. One participant indicated:

"There are kids who cannot even live without taking these substances, like addicted. You will find learners in the class shaking yes.... and even sneak out to go and take this substance - yes."

Schools have a code of conduct and policies in place to deal with learners who may be found in possession of substances. Less punitive measures may involve referring learners for counselling and treatment by social workers and psychologists. If a learner is found intoxicated at the school gate, he or she may not be allowed into the school premises. In extreme cases, learners may be suspended from school as explained by the participant whose 
explanation is indicated below:

"the school always suspends those learners if you are seen that you are really drunk. Then the school will send you home, suspend you. The suspension can be for a term or for the whole year. And, ehh if it is detected from the gate that this person is drunk or intoxicated the person will not be allowed to come in the school.

\subsection{Easy Access /Availability of Too Many Liquor Outlets}

The consensus and concern raised by all the participants of the study was the liquor outlets that are found all over the community within the residential areas, which makes alcohol and other substances easily accessible to school going youth. One participant explained:

"Like every place where you go you find a bar, and the schools are also close to the bars and houses are close to the bars...sometimes it is very easy for these children to drown in because of the accessibility"

In support of that, another respondent added:

"you find a house with a cuca shop and then parents, they allow their children to hang around at the bar there"

A cucashop is a term used in northern Namibia to refer to drinking outlets and it is a synonym for a shebeen. This finding was confirmed by SIAPAC (2002), Shikoyeni (2017), Kauaria, Kaundjua and Mufune (2015), and Nowak et al. (2018) who confirmed that alcohol is easily accessible all over the country which increases drinking behaviour of Namibians. These findings are a serious contravention of the Liquor Act No 6 of 1998 of Namibia which stipulates the need to avoid, as far as possible, the establishment of licensed premises in the vicinity of schools or places of worship (Government of the Republic of Namibia, 1998, 16 A iii). The Namibia Human Development report states that the alcohol industry is the third largest employer, after government services, agriculture and fisheries in Namibia, and thus liquor outlets are readily available in the communities (UNDP, 1999). The report added that alcohol is also easily available at liquor stores and restaurants in Namibia. There are therefore, more liquor outlets compared to other types of business in many Namibian towns. A qualitative study by Chibaya (2016) focussed on the availability of illegal drugs in Namibia and found that the availability of illegal drugs to secondary school learners in Namibia is a major concern. Most of the participants complained that schools are located next to the bars and children can easily buy alcohol from these liquor outlets close to the school. One participant commented:

"our school is surrounded by shebeens."

Ndondo (2016) supports the findings by asserting that the availability of alcohol in close proximity of schools may be tempting to learners to take into school premises. Because of the close proximity of bars, some school going learners drink alcohol and other substances while they are on their way to school in the mornings or in the afternoon when they return from school. Another participant said:

"after school, on their way to home they start (drinking), or even on the way to come to school early morning they do have."

The findings align with the results of Milam, Lindstrom-Johnson, Furr-Holden \& Bradshaw (2016), who state that the presence of alcohol outlets in communities to and from school routes as well as in close proximity of schools provides an opportunity to school going children to experiment with alcohol and substances. Consequently, some children may end up drinking alcohol excessively or using other substances to the point of habitual behaviour. Moreover, some parents seem to condone and even support the presence of shebeens. Participants reported that some parents are owners of the business of shebeens themselves and they expect their children to work in the shebeens selling liquor after school. The parents who are not owners of shebeens also support shebeens as customers. One participant stated that:

"Those parents own shebeens. Sometime, after school, these learners are the one that run shebeens and they tend to misuse alcohol."

The findings are consistent with a UNICEF evaluation report on the "My Future is my Choice" life skills programme for adolescents in Namibian schools, which indicated that parents' drinking behaviour and the sending of their children to buy alcohol is a risk factor to substance abuse amongst the youth (UNICEF, 2008). Respondents also reported that some parents are poor role models as they drink alcohol with their children. One participant indicated that:

"You will find parents in a cuca shop with their children drinking together yes, like in cuca shop they will be drinking tombo and sharing." 
The findings are consistent with literature (Maree et al., 2008; Mudhovozi et al., 2014; Ndondo, 2016) which reports that youth tend to imitate inadequate role models such as parents, guardians and caregivers who are using substances. The Namibian Human Development report also confirmed that the way children are brought up, the drinking habits of families and the communities, and parents sending children to shebeen outlets at a tender age result in children seeing alcohol consumption as a normal way of life (UNDP, 1999). In line with more than one hundred countries worldwide that are banning the purchasing of alcohol by children (Morleo et al., 2013), the Namibian Liquor Act No 6 of 1998 also prohibits the selling of liquor to children younger than 18 years. Participants reported that alcohol outlets seem to ignore the legal provisions and end up selling alcohol to children under 18 years, which increases the chances of underage drinking. One participant stated:

"In bars and bottles stores and pubs at least there are regulations that prevent children from entering, but in shebeens in the locations and shantytowns and in villages anybody could come and enter and get alcohol. Everybody is free. So, the shebeens play a much important role in distributing alcohol to minors."

The findings are consistent with Chibaya (2016) who argue that children are unfortunately allowed in shebeens because they may attract more business and support the business financially. The Namibian Human Development report indeed confirmed that contrary to the legislation that prohibits the selling of alcohol to children younger than 18 years, minor children in fact have easy access to alcohol at shebeens and even at licenced liquor outlets (UNDP, 1999). In a mobile based study by Keulder (2009) that aimed at seeking the views of children on issues that affect them in the community, children between the ages of 10 and 13 years strongly expressed their opinion that stricter laws should be passed against selling alcohol to children less than 18 years of age in Namibia. Liquor outlets are controlled by the liquor act which stipulates the business operating hours of liquor outlets. Participants shared a concern about the operating hours as some businesses ignore the prescribed operating hours by remaining open day and night. As a result, there is no time for communities finds little time to rest at night which could be disturbing for school going children who needs proper rest at night to concentrate on academic work. One participant explained:

"The operations hours and licences are...are challenges. Iya...ten o clock, I think is a reasonable time. But now you will find some bars that have got licenses that go up to 2 o'clock in the morning ehh...if it was 10 o'clock across that would have been better, and the police would have been very much effective in regulating that. But for now, others will regulating until 10 o'clock. What will you do if 10'o clock is closing time for this shebeen, he will proceed to another one that will operate until $4 o^{\prime}$ 'clock and $2 o^{\prime}$ 'clock in the morning and then ee...ee...it woundn't serve any purpose any longer because once this one is close he will go to the other one and it is between that time you will find lots of accidents taking place. Because lot of accident take place between 10 and 11 and 2, between 10 and 2. Because those people commute between places to go and look for alcohol, but if it was flat 10 o'clock 22 hours in the evening that would been better."

These findings are supported by Maree et al. (2008) whose findings have confirmed that alcohol outlets in Namibia, especially the unlicensed ones, open day and night. The Namibian Human Development report also confirmed that some shebeens in Namibia offer alcoholic beverages to its customers on a 24-hour basis (UNDP, 1999). The Liquor Act of Namibia provides for the regulations and standards that need to be in place before a licence can be issued to liquor outlets. Participants explained the difficulties prospective business people encounter to acquire a liquor licence, which leave some shebeen owners with no option but to run the shebeen without any license. One participant stated

"Obtaining a licence to open a shebeen is not easy, because people should follow the strict regulations. Perhaps some shebeens are opened illegally and have not been following the regulations and are also not hindered from operating either."

Contrary to these findings on the difficulties to obtain a liquor licence, both Maree et al. (2008) and (UNDP, 1999) claim that the sale of alcohol has become uncontrollable as many people possess trade licences and shebeens in Namibia. The Namibian Police is tasked by the Liquor Act 1998 to monitor liquor outlets, and to ensure that they are operating within the prescribed limits. Participants reported the challenge and resistance that the police officers encounter from the community members to exercise law and order. One participant claimed:

"the police is trying their level best to control the operation of shebeens but sometimes community members, business people themselves they try too...fight them back."

Except for law enforcement, Namibian communities have already existing cultural norms to control the opening and closing of businesses, including shebeens, to ensure that agricultural activities must first be carried out before other business activities are considered. One participant explained how traditional authorities stipulate business 
hours in the community:

"At our village, it is a law of the village that the earlier one could open during the summer time when there is no work is 10 o'clock after watering the animals, iya, 10 o'clock in the morning. And then when it harvesting time, cultivation and harvesting is 11 o'clock iya"

A desire was further expressed to have the number of liquor reduced in the community, and to completely separate liquor outlets from residential areas in the community. One participant stated:

"if the location could be made just for houses, that will be good and shebeens on the other side that would be possible"

As much as the issue of many liquor outlets in the community is of concern, some participants complained that substances are even found on the streets, especially the unlicensed alcohol, cigarettes and the illegal drugs that are smuggled illegally in the country. Certainly, a different type of measure has to be considered for substances that are available on the streets. One participant stated:

"those whiskies and "Yes" cigarettes, .... those illicit drugs...they are in the streets, people are selling them mobile,.... they are not as such at the bar or certain people who are selling these, people are just selling in the streets."

These items sold on the street are the substances such as the unrecorded cigarettes, alcohol and drugs that were smuggled into the country due to poor border controls. This is confirmed by Peltzer, Ramlagan, Johnson and Phaswana-Mafuya (2010) who claim that poorly controlled border posts that also have a large number of people crossing a border offer opportunities for smuggling illegal substances.

\section{Discussion}

This qualitative study explored the views of secondary school teachers and hostel matrons on the landscape of substance abuse amongst the youth at a border town community in northern Namibia. It was the first study of this nature to be conducted in a border town within a rural community, and the findings may be useful for programme, policy and law reform.

The findings of this study confirmed that learners and young people are using a variety of alcoholic beverages. Legislation on the legal age limit of selling alcohol to children under the age of 18 does not seem to be a deterrence to the youth to obtain alcohol. The study found that little children may already be offered traditional brews by caregivers with the intention of feeding the children, but with complete ignorance of the alcohol content of the traditional brew. The study further indicated that traditional brews are also taken to school to be taken during school breaks. However, the taking of traditional brews is not a preference by the youth, but rather due to hunger and starvation of the learners and poverty. It appears that drinking of traditional brews becomes acceptable at a much older age of young adulthood. The smoking of cigarettes by the youth in this study seems to be based on the availability of very cheap cigarettes imported into the country. Thus, under circumstances where normal prizes of cigarettes apply, school learners might have been hesitant to use cigarettes. School going youths in this study are exposed to cannabis and as such they come into conflict with the law. A surprising observation of this study is that law enforcement was more efficient in the situation of cannabis as an illegal substance used by the youth. However, law enforcement of the legislation related to alcohol seems to be low. The study found that there is a low response by the police and law enforcement on matters pertaining to alcohol such as drinking outlets in close proximity to schools, selling of alcohol to children under 18 years of age and the operating hours of shebeens that seems not to be under any control.

Furthermore, learners taking alcohol to school and using it on secluded school premises was the second theme in this study. Attempts by school administrators to ensure that the school environment is free from substances by testing learners for alcohol and drugs were found amongst the measures at the schools. The third theme of this paper focussed on the easy accessibility and availability of substances in the community. Despite the prohibition in the Liquor Act of Namibia, drinking outlets were found to be in close proximity of schools, which is indeed a temptation for school going youth, and this increases the likelihood of substance abuse by the youth. The role of parents as shebeen owners and their expectation for children to work in shebeens and even sending children to buy alcohol at shebeens also exposes children to the culture of drinking. A worrisome finding that is probably unique to border town communities is the availability of substances smuggled from across the borders into the Namibian streets.

\section{Conclusion}

One of the implications flowing from this research is the need for advocacy and stricter law enforcement on the 
selling of alcohol to the youth, the close proximity of shebeens to schools and residential hours and the operating hours of shebeens. Parental education needs to be introduced to raise awareness about the negative influences of shebeens to school going children. Moreover, drastic measures need to be considered to completely remove liquor outlets from residential areas and schools. The community at large may also need to be educated and to take a firmer stand against the presence of shebeens near schools and within the community. However, the results of the study cannot be generalized to a larger population because the study was conducted at a single border town in northern Namibia, hence the study did not include the other border towns. Furthermore, the study only focussed on the views of secondary school teachers and hostel matrons from selected schools at the border town. Therefore, this study can be replicated in other border towns with a larger sample size. In this study, the views of educators on substance abuse amongst youth were examined. Future research could focus on the views of learners themselves or the views of parents on substance abuse.

\section{Funding}

This study was wholly funded by the National Commission on Research Science and Technology of Namibia and the National Research Foundation of South Africa.

\section{Competing Interests Statement}

The authors declare that there are no competing or potential conflicts of interest regarding the publication of the paper.

\section{References}

Alhyas, L., Ozaibi, N. A., Elarabi, H., El-Kashef, A., Wanigaratne, S., Almarzouqi, A., Alhosani, A., \& Hamad Al Ghaferi, H. (2015). Adolescents' perception of substance use and factors influencing its use: a qualitative study in Abu Dhabi. Journal of the Royal Society of Medicine Open, 6(2), 1-12. https://doi.org/10.1177/2054270414567167

Barth, K., \& Hubbard, D. (2009). Alcohol and youths: Suggestions for law reform. Windhoek: LAC.

Chibaya, G. (2016). Illicit drug use by secondary school learners in Windhoek, Namibia (MA thesis in Public Health, UNISA, Pretoria, South Africa).

ESPAD Group. (2015). ESPAD report 2015: Results from the European school survey project on alcohol and other drugs. Lisbon, Portugal: EMCDDA.

Government of the Republic of Namibia. (1998). Liquor Act 6 of 1998. Windhoek, Namibia: Government of Namibia.

Joubert, R., Sughrue, J., \& Alexander, D. M. (2013). Search and seizure of learners in schools in a constitutional democracy: A comparative analysis between South Africa and the United States. De jure, 46(1), 114-133.

Kauaria, L N., Kaundjua, M. B., \& Mufune, P. (2015). Drinking and its effects on risk behaviour amongst secondary school going youth in Windhoek. Journal for Studies in Humanities and Social Sciences, 4(1), 2026-7215.

Kazembe, L. N., \& Neema, I. (2015). Drugs and drug control in Namibia. In A. Kalunta-Crumpton (Ed.). Drugs and drug control: Pan-African perspective. Windhoek, Namibia: Ashgate Publisher. Retrieved from https://www.researchgate.net/publication/273124879_Drugs_and_Drug_Control_in_Namibia [accessed Dec 17 2018]. https://doi.org/10.4324/9781315599335-5

Keulder, T. (2009). Overall report: Catching the voice of the born-free generation of Namibia through mobile phones. Swakopmund, Namibia: Namibia Institute for Democracy NID.

Lightfoot E., Maree, M., \& Ananias, J. (2009). Exploring the relationship between HIV and alcohol use in a remote Namibian mining community. African Journal of AIDS Research, 8(3), 321-327. https://doi.org/10.2989/AJAR.2009.8.3.8.929

Maree, M., Ananias, J., Lightfoot, E., Katondoka, K., \& Ashton, D. (2008). Factors leading to drug and alcohol use and abuse by Namdeb employees: A comprehensive mixed-methods investigation. Unpublished research report.

Milam, A. J., Lindstrom-Johnson, S., Furr-Holden, C. D. M., \& Bradshaw, C. P. (2016). Alcohol outlet density and substance use amongst high scholars. Journal of Community Psychology, 44(7), 819-832. https://doi.org/10.1002/jcop.21802

Ministry of Education, Arts and Culture and UNICEF. (2018). Namibia's national safe schools' framework: Part B 
practical guide for building safe schools. Okahandja, Namibia.

Ministry of Health and Social Services/Namibia Statistics Agency. (2014). Namibia Demographic and Health Survey 2013. Windhoek, Namibia.

Ministry of Health and Social Services (MOHSS)/Namibia Statistics Agency (NSA). (2014). Namibia Demographic and Health Survey 2013.

Morleo, M., Cook, P. A., Elliott, G., \& Phillips-Howard, P. A. (2013). Parental knowledge of alcohol consumption: A cross sectional survey of 11-17-year-old schoolchildren and their parents. BMC Public Health, 13, 412. https://doi.org/10.1186/1471-2458-13-412

Moss, H. B., Chen, C. M., \& Yi, H. Y. (2014). Early adolescent patterns of alcohol, cigarettes, and marijuana polysubstance use and young adult substance use outcomes in a nationally representative sample. Drug and Alcohol Dependence, 136, 51-62. https://doi.org/10.1016/j.drugalcdep.2013.12.011

Mudhovozi, P., Maunganidze, L., Maseko, M., Ngwenya, F., \& Netshikweta, L.M. (2014). Patterns of substance abuse among high school students. African Journal for Physical, Health Education, Recreation and Dance, 1(2), 348-358.

Ndondo, B. (2016). A literature review on drug and substance use amongst youth and young women in South Africa. Soul City Institute Drug Abuse Youth South Africa Final. Retrieved 10 January, 2019, from https://www.soulcity.org.za/resources/research/literature-reviews/soul-city-institute-drug-abuse-youth-south -africa.pdf/view

Nowak, M., Papiernik, M., Mikulska, A., \& Czarkowska-Paczek, B. (2018). Smoking, alcohol consumption, and illicit substances use among adolescents in Poland. Substance Abuse Treatment, Prevention, and Policy, 13(1), 42. https://doi.org/10.1186/s13011-018-0179-9

Olawole-Isaac., Ogundipe, O., Amoo, E. O., \& Adeloye, D. (2018). Substance use amongst adolescents in sub-Saharan Africa: A systematic review and meta-analysis. The South Africa Journal of Child Health, 12(2b), 79-83. https://doi.org/10.7196/SAJCH.2018.v12i2b.1524.

Peltzer, K., Ramlagan, S., Johnson, B. D., \& Phaswana-Mafuya, N. (2010). Illicit drug use and treatment in South Africa: A review. Substance Use and Misuse, 45(13), 2221-2243. https://doi.org/10.3109/10826084.2010.481594

Republic of Namibia. (2010). Tobacco Products Control Act 1 of 2010. Windhoek, Namibia: Government Print. Retrieved from https://wipolex.wipo.int/en/text/225494

Shikoyeni, H. N. (2017). Exploring the psycho social determinants of heavy alcohol drinking amongst women in Oshana, Namibia (MA thesis, University of Western Cape, Cape Town, South Africa) Retrieved from http://hdl.handle.net/11394/5621

Social Impact Assessment and Policy Analysis Corporation (SIAPAC). (2002). Nationwide KAP baseline survey on alcohol and drug use and abuse in Namibia. Windhoek, Namibia: Ministry of Health and Social Services, and the Ministry of Agriculture, Water and Rural Development.

Strijdom, J. L., \& Angell, O. H. (1998). Substance use among the youth in Namibia, Centre for the Partnership in Development, Ministry of Health and Social Services \& University of Namibia. Unpublished research report.

United Nations Development Programme [UNDP]. (1999). Namibia Human Development Report. Windhoek, Namibia: United Nations Development Programme.

UNESCO, UNODC, WHO. (2017). Education sector responses to the use of alcohol, tobacco and drugs: Good policy and practice in health education. Retrieved from http://unesdoc.unesco.org/images/0024/002475/247509e.pdf

UNICEF. (2006). HIV and AIDS knowledge, attitudes, practice and behavior (KAPB) study in Namibia. Retrieved from https://www.ean.org.na:8080/xmlui/handle/123456789/299

UNICEF. (2008). Evaluation of 'My Future is my Choice' peer education life skills programme in Namibia. Identifying strengths, weaknesses and areas for improvement. Windhoek, Namibia: UNICEF.

World Health Organization [WHO]. (2004). Global status report on alcohol and health. Geneva, Switzerland: WHO.

World Health Organization [WHO]. (2018). Global status report on alcohol and health. Geneva, Switzerland: WHO. 


\section{Copyrights}

Copyright for this article is retained by the author(s), with first publication rights granted to the journal.

This is an open-access article distributed under the terms and conditions of the Creative Commons Attribution license (http://creativecommons.org/licenses/by/4.0/). 